\title{
هִ The oculomotor-tentorial triangle. Part 2: a microsurgical workspace for vascular lesions in the crural and ambient cisterns
}

\author{
Justin R. Mascitelli, MD, Sirin Gandhi, MD, Ali Tayebi Meybodi, MD, and Michael T. Lawton, MD \\ Department of Neurosurgery, Barrow Neurological Institute, Phoenix, Arizona
}

OBJECTIVE Pathology in the region of the basilar quadrifurcation, anterolateral midbrain, medial tentorium, and interpeduncular and ambient cisterns may be accessed anteriorly via an orbitozygomatic (OZ) craniotomy. In Part 1 of this series, the authors explored the anatomy of the oculomotor-tentorial triangle (OTT). In Part 2, the versatility of the OTT as a surgical workspace for treating vascular pathology is demonstrated.

METHODS Sixty patients with 61 vascular pathologies treated within or via the OTT from 1998 to 2017 by the senior author were retrospectively reviewed. Patients were grouped together based on pathology/surgical procedure and included 1) aneurysms ( $n=19) ; 2)$ posterior cerebral artery (PCA)/superior cerebellar artery (SCA) bypasses $(n=24) ; 3)$ brainstem cavernous malformations (CMs; $n=14$ ); and 4) tentorial region dural arteriovenous fistulas (dAVFs; $n=4)$. The majority of patients were approached via an $\mathrm{OZ}$ craniotomy, wide sylvian fissure split, and temporal lobe mobilization to widen the OTT.

RESULTS Aneurysm locations included the $P_{1}-P_{2}$ junction $(n=7), P_{2 A}$ segment $(n=9), P_{2 / 3}(n=2)$, and basilar quadrification $(n=1)$. Aneurysm treatments included clip reconstruction $(n=12)$, wrapping $(n=3)$, proximal occlusion $(n=2)$, and trapping with $(n=1)$ or without $(n=1)$ bypass. Pathologies in the bypass group included vertebrobasilar insufficiency $(\mathrm{VBI} ; n=3)$ and aneurysms of the basilar trunk $(n=13)$, basilar apex $(n=4), P_{1}$ PCA $(n=2)$, and $s_{1} S C A(n=2)$. Bypasses included $M_{2}$ middle cerebral artery (MCA)-radial artery graft (RAG) $-P_{2} P C A(n=8), M_{2} M C A$-saphenous vein graft $(S V G)-P_{2} P C A(n=3)$, superficial temporal artery $(S T A)-P_{2} P C A(n=5)$ or STA- $S_{1} S C A(n=3), s_{1} S C A-P_{2} P C A(n=1)$, $V_{3}$ vertebral artery $(V A)-R A G-S_{1} S C A(n=1), V_{3} V A-S V G-P_{2} P C A(n=1)$, anterior temporal artery-S $S_{1} S C A(n=1)$, and external carotid artery $(E C A)-S V G-S_{1} S C A(n=1)$. CMs were located in the midbrain $(n=10)$ or pontomesencephalic junction $(n=4)$. dAVFs drained into the tentorial, superior petrosal, cavernous, and sphenobasal sinuses. High rates of aneurysm occlusion (79\%), bypass patency (100\%), complete CM resection (86\%), and dAVF obliteration (100\%) were obtained. The overall rate of permanent oculomotor nerve palsy was $8.3 \%$. The majority of patients in the aneurysm $(94 \%)$, CM $(93 \%)$, and dAVF (100\%) groups had stable or improved modified Rankin Scale scores.

CONCLUSIONS The OTT is an important anatomical triangle and surgical workspace for vascular lesions in and around the crural and ambient cisterns. The OTT can be used to approach a wide variety of vascular pathologies in the region of the basilar quadrifurcation and anterolateral midbrain.

https://thejns.org/doi/abs/10.3171/2018.2.JNS173141

KEYWORDS oculomotor triangle; ambient cistern; crural cistern; pontomesenphalic junction; posterior circulation revascularization; posterior circulation aneurysms; brainstem cavernous malformation; tentorial dural arteriovenous fistula; vascular disorders; surgical technique

\footnotetext{
ABBREVIATIONS $A C A=$ anterior cerebral artery; $\mathrm{AChA}=$ anterior choroidal artery; $\mathrm{ATA}=$ anterior temporal artery; $\mathrm{CM}=$ cavernous malformation; $\mathrm{CN}=\mathrm{cranial}$ nerve; $\mathrm{COT}$ = carotid-oculomotor triangle; $\mathrm{CS}$ = cavernous sinus; $\mathrm{CTA}=\mathrm{CT}$ angiography; $\mathrm{dAVF}=$ dural arteriovenous fistula; $\mathrm{DSA}=$ digital subtraction angiography; $\mathrm{ECA}=$ exter nal carotid artery; ICA = internal carotid artery; ICG = indocyanine green; $M C A=$ middle cerebral artery; $\mathrm{mRS}=$ modified Rankin Scale; ONP = oculomotor nerve palsy; $\mathrm{OTT}=$ oculomotor-tentorial triangle; $\mathrm{OZ}$ = orbitozygomatic; $\mathrm{PCA}=$ posterior cerebral artery; $\mathrm{PCOA}=$ posterior communicating artery; $\mathrm{PCP}=$ posterior clinoid process; $\mathrm{PIA}$ = posterior interhemispheric approach; RAG = radial artery graft; $\mathrm{SAH}$ = subarachnoid hemorrhage; $\mathrm{SBS}=$ sphenobasal sinus; $\mathrm{SCA}=$ superior cerebellar artery; $\mathrm{SCIT}=$ supracerebellar infratentorial; SPS = superior petrosal sinus; STA = superficial temporal artery; SVG = saphenous vein graft; TS = tentorial sinus; VA = vertebral artery; VBI $=$ vertebrobasilar insufficiency.

SUBMITTED December 15, 2017. ACCEPTED February 16, 2018.
}

INCLUDE WHEN CITING Published online June 29, 2018; DOI: 10.3171/2018.2.JNS173141. 
$\mathrm{P}$ ATHOLOGY in the region of the basilar apex, anterolateral midbrain, medial tentorium, and interpeduncular and ambient cisterns may be accessed anteriorly via an orbitozygomatic (OZ) craniotomy and a transsylvian approach. Previously described triangles to access this region include the optico-carotid triangle, the carotid-oculomotor triangle (COT), and supracarotid triangle. The COT provides the largest surgical workspace and is the window of access for most basilar apex aneurysms. However, the COT is not favorable for bypasses because it routes deep to the sensitive oculomotor nerve and contains the $\mathrm{P}_{1}$ posterior cerebral artery (PCA) segment, which harbors thalamoperforators that are intolerant of temporary occlusion during anastomosis.

In Part 1 of this series we introduced the oculomotortentorial triangle (OTT) as a potential workspace for vascular pathology in this region. The OTT routes lateral and posterior to the oculomotor nerve where arterial segments are more superficial and less populated with critical perforators. Our favorable experience utilizing the OTT for bypasses led us to expand its use for other pathologies involving this anatomy, including aneurysms, cavernous malformations (CMs), and dural arteriovenous fistulas (dAVFs). In Part 2, we review the vascular pathology treated within the OTT and analyze the associated clinical and radiographic outcomes after treatment.

\section{Methods}

\section{Surgical Anatomy and Operative Technique}

The majority of patients were treated via an OZ craniotomy. While the OTT may be accessed via a pterional, orbital-pterional, or subtemporal craniotomy, the OZ craniotomy provides the best vantage point and widest working space. Following the craniotomy and dural opening, microdissection begins with splitting of the sylvian fissure followed by opening the arachnoid of the optico-carotid cistern, exposing the optic nerve, supraclinoid internal carotid artery (ICA), and proximal middle cerebral artery (MCA) and anterior cerebral artery (ACA). A wide sylvian fissure split is important to improve visualization of the OTT. The next step is to systematically release attachments to the temporal lobe so that it can be retracted in a posterolateral direction. Further release of the medial temporal lobe is accomplished by dissecting the anterior choroidal artery (AChA) along its cisternal segment. This maneuver will open the tentorial incisura and crural cistern, identify the $\mathrm{P}_{2}$ segment, liberate cranial nerve (CN) III, expose the cerebral peduncle, and release the medial temporal lobe. At this point, a retractor can safely be placed on the temporal lobe with the tip on the uncus, which will widen the COT and OTT (Fig. 1). Further maneuvers to widen the OTT include resection of the uncus ${ }^{20}$ and drilling of the posterior clinoid process (PCP). These maneuvers were rarely performed. An anterior petrosectomy (i.e., Kawase approach) may also be necessary to view the pontomesencephalic junction.

The final dissection is lesion dependent. For aneurysms, the PCA is identified and followed posteriorly toward the aneurysm. Proximal control is obtained early by identifying the $\mathrm{P}_{1}$ segment and the posterior communicating ar- tery (PCoA) first. For bypasses, the PCA or superior cerebellar artery (SCA) is identified and a segment is prepared for bypass. For CMs, the midbrain is inspected for obvious signs of the lesion or more subtle discoloration that can direct the point of entry. For dAVFs, the vascular anatomy is exposed and an indocyanine green (ICG) videoangiogram is performed to understand the point of shunting.

\section{Patients and Pathology}

IRB approval was obtained to perform this study. This is a retrospective review of all patients with vascular pathology treated via the OTT by the senior author from 1998 to 2017. Patients were grouped together based on pathology/surgical procedure. The first group includes aneurysms treated within the OTT $(n=19)$. The second group includes bypasses performed to vessels within the OTT $\left(\mathrm{P}_{2 \mathrm{~A}}\right.$ or $\mathrm{s}_{1}$ segments) for pathology outside of the OTT, such as vertebrobasilar insufficiency (VBI) or aneurysms of the basilar trunk, basilar apex, $\mathrm{P}_{1}$ segment of the PCA, or $\mathrm{s}_{1}$ segment of the SCA proximal to CN III $(n=24)$. The third group includes CMs of the midbrain and pontomesencephalic junction $(n=14)$. The fourth group includes dAVFs in the medial tentorial region within the OTT $(n=4)$.

Preoperative baseline information, operative data, and clinical/radiographic outcomes were assessed by reviewing the electronic medical record, operative reports, and radiological examinations. Clinical outcome was assessed using the modified Rankin Scale (mRS) with good outcome defined as mRS score $0-2$. The final rate of oculomotor nerve palsy (ONP) was determined among the aneurysm, CM, and dAVF patients only, given the severe clinical condition of the patients in the bypass cohort. Radiological outcome was determined according to pathology. Aneurysms were classified as occluded or not occluded on postoperative CT angiography (CTA) or digital subtraction angiography (DSA). Bypass patency was graded on postoperative CTA or DSA. Extent of CM resection was graded on the postoperative MRI. dAVF occlusion was graded on postoperative CTA or DSA.

\section{Results}

\section{Aneurysms}

Eighteen patients had a total of 19 aneurysms treated via the OTT (Table 1). The average age was 48 years and half the patients were female. Eight patients presented with subarachnoid hemorrhage (SAH) and the preoperative $\mathrm{mRS}$ score was poor in more than half $(55.6 \%)$ of the patients. Specific aneurysm locations were the $\mathrm{P}_{1}-\mathrm{P}_{2}$ junction $(n=7), P_{2 A}$ segment $(n=9), P_{2 / 3}$ segments $(n=$ 2 ), and 1 basilar artery quadrifurcation aneurysm. One patient had blister aneurysms of the basilar quadrifurcation and $\mathrm{P}_{1}-\mathrm{P}_{2}$ junction. Aneurysm morphologies were 12 saccular, 4 dolichoectatic, 2 blister, and 1 fusiform. Four aneurysms were giant, 2 were thrombotic, and 1 was recurrent after endovascular coiling. Seventeen patients received an OZ craniotomy and 1 received only a pterional craniotomy. Twelve aneurysms were clip reconstructed (Fig. 2), 3 were wrapped (Fig. 3), 2 were occluded proximally, 1 was trapped with a superficial temporal artery (STA)-PCA bypass, and 1 was trapped without a bypass. 
Mascitelli et al.

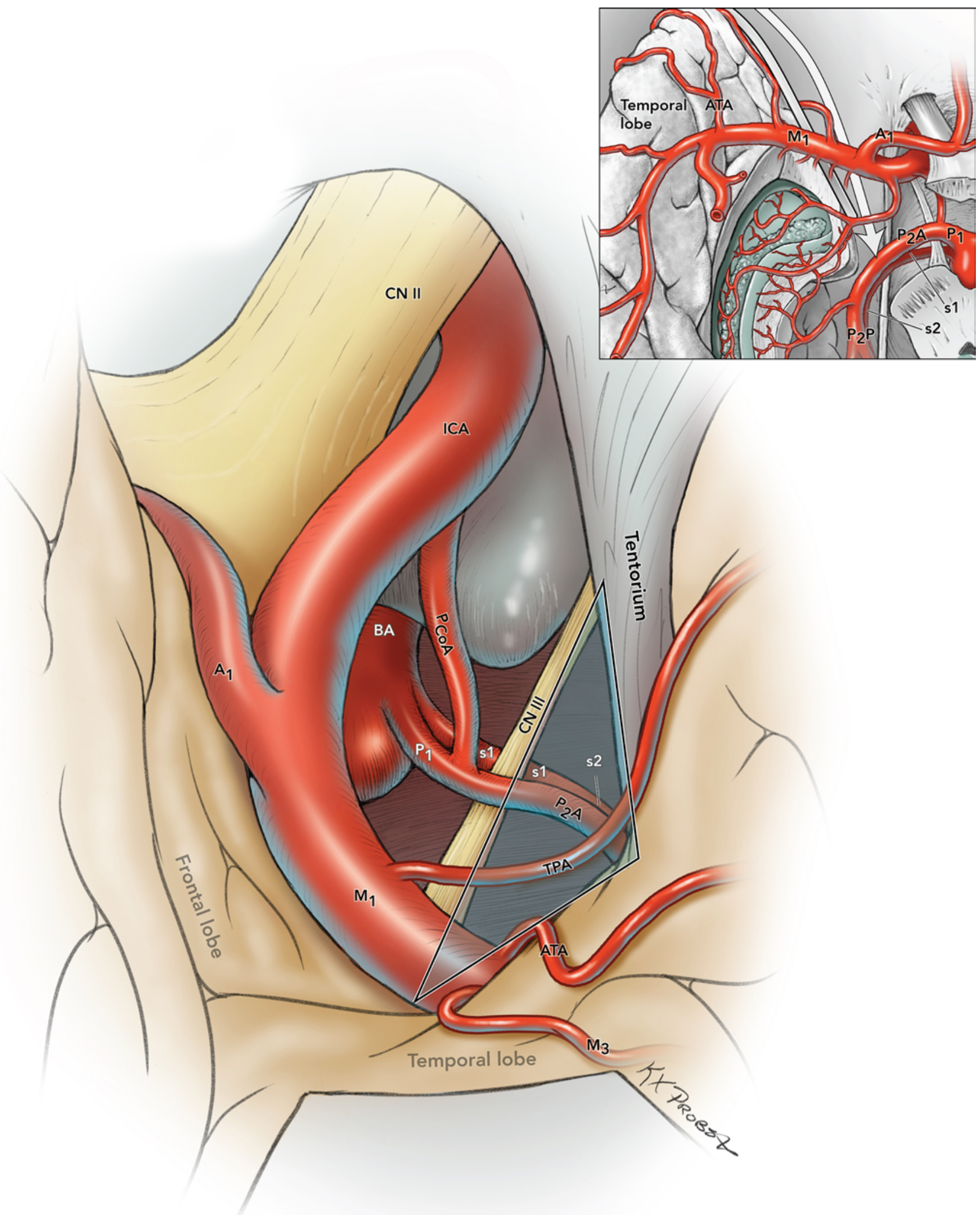

FIG. 1. Illustration of the OTT. The OTT is bordered medially by CN III, laterally by the tentorium, and posteriorly by the retracted temporal lobe. The contents of the triangle include the anterolateral midbrain (including the cerebral peduncle), the $\mathrm{P}_{2}$ segment of the PCA, and the lateral pontomesencephalic segment $\left(s_{2}\right)$ of the SCA. BA = basilar artery; TPA = temporal polar artery. Copyright Michael T. Lawton. Published with permission. Figure is available in color online only. 
TABLE 1. PCA aneurysms within the OTT

\begin{tabular}{|c|c|c|}
\hline Variable & No. & $\%$ \\
\hline No. of patients & 18 & \\
\hline No. of aneurysms & 19 & \\
\hline Mean age (yrs) & 48 & \\
\hline \multicolumn{3}{|l|}{ Sex } \\
\hline Females & 9 & 50 \\
\hline Males & 9 & 50 \\
\hline $\mathrm{SAH}$ & 8 & 44 \\
\hline \multicolumn{3}{|l|}{ Preoperative mRS score } \\
\hline Good & 8 & 44 \\
\hline Poor & 10 & 56 \\
\hline \multicolumn{3}{|l|}{ Aneurysm location } \\
\hline$P_{1}-P_{2}$ junction & 7 & 37 \\
\hline $\mathrm{P}_{2 \mathrm{~A}}$ & 9 & 47 \\
\hline $\mathrm{P}_{2 \mathrm{~B}}$ & 2 & 11 \\
\hline Basilar & 1 & 5 \\
\hline \multicolumn{3}{|l|}{ Aneurysm morphology } \\
\hline Saccular & 12 & 63 \\
\hline Dolichoectatic & 4 & 21 \\
\hline Blister & 2 & 11 \\
\hline Fusiform & 1 & 5 \\
\hline \multicolumn{3}{|l|}{ Other aneurysm features } \\
\hline Giant size & 4 & 21 \\
\hline Thrombotic & 2 & 11 \\
\hline \multicolumn{3}{|l|}{ Treatment } \\
\hline Clip reconstruction & 12 & 63 \\
\hline Wrapping & 3 & 16 \\
\hline Proximal occlusion & 2 & 11 \\
\hline Trapping w/ bypass & 1 & 5 \\
\hline Trapping w/o bypass & 1 & 5 \\
\hline \multicolumn{3}{|l|}{ Outcome } \\
\hline Incomplete aneurysm obliteration* & 4 & 21 \\
\hline Aneurysm retreatment & 1 & 5 \\
\hline Permanent ONP & 1 & 6 \\
\hline mRS score stable or improved at follow-up & 17 & 94 \\
\hline Good outcome (mRS score 0-2) & 15 & 83 \\
\hline Death & 0 & 0 \\
\hline
\end{tabular}

* Three cases of aneurysm wrapping.

One $\mathrm{P}_{2 / 3}$ aneurysm was proximally occluded via the OTT. The other $\mathrm{P}_{2 / 3}$ aneurysm was clip reconstructed via a subtemporal approach. The $\mathrm{P}_{2 \mathrm{~A}}$ portion of the reconstruction was within the OTT and the $\mathrm{P}_{2 \mathrm{P}} / \mathrm{P}_{3}$ portion was posterior to the OTT. Aneurysm thrombectomy was performed in 2 cases. There were no instances of intraoperative rupture.

All aneurysms were completely occluded except for the 3 cases that were wrapped and 1 case of a giant fusiform $\mathrm{P}_{1}-\mathrm{P}_{2}$ aneurysm that was initially clip reconstructed but recurred and required trapping. Perioperative complications included ONP in 5 patients $(1$ complete and permanent, 4 partial and transient), 2 neurological deficits (homonymous hemianopsia and hemiparesis), and 1 PCA occlusion.
There was one delayed wound infection. At discharge, all mRS scores were stable or improved except for 1 patient in which the mRS score worsened from 2 to 3 (the patient with the PCA occlusion). At follow-up, all mRS scores were stable or improved except the same patient with an $\mathrm{mRS}$ score of 3 . The majority of patients had a good clinical outcome (83\%). There were no deaths (Table 1).

\section{PCA and SCA Bypass}

Bypass into the OTT for pathology outside the OTT was performed in 24 cases (Table 2). The average age was 59 years and the majority of patients were male $(71 \%)$. Pathologies included 3 cases of VBI, 13 basilar trunk aneurysms, 4 basilar apex aneurysms, 2 PCA $\left(\mathrm{P}_{1}\right)$ aneurysms, and 2 SCA $\left(\mathrm{s}_{1}\right)$ aneurysms. Only 4 of the patients with aneurysms presented with SAH. The rest presented with symptoms of either ischemia or mass effect on the brainstem. The majority of the basilar trunk aneurysms were giant, dolichoectatic, and thrombotic. The 4 basilar apex aneurysms were giant; 2 were thrombotic, 1 was recurrent after coiling, and 1 was recurrent after wrapping. One SCA aneurysm was giant and thrombotic and the other was recurrent after coiling. One PCA aneurysm was dissecting and iatrogenic following pituitary surgery and the other was fusiform. Preoperative functional status was poor in the majority of patients $(66.7 \%)$.

An OZ craniotomy was performed in 22 cases and a combined far lateral/subtemporal craniotomy was performed in 2 cases. Bypasses included $\mathrm{M}_{2}$ MCA- $\mathrm{P}_{2}$ PCA using a radial artery graft (RAG; $\mathrm{n}=8$ ) or saphenous vein graft (SVG; $n=3$, Fig. 4), STA- ${ }_{2}$ PCA $(n=5)$, STA- $\mathrm{s}_{1}$ SCA $(n=3), s_{1}$ SCA- $P_{2}$ PCA in situ bypass $(n=1), V_{3}$ vertebral artery (VA)-RAG- $\mathrm{s}_{1}$ SCA $(\mathrm{n}=1), \mathrm{V}_{3} \mathrm{VA}-\mathrm{SVG}-\mathrm{s}_{1}$ SCA $(n=1)$, anterior temporal artery $($ ATA $)-s_{1}$ SCA $(n=$ 1), and external carotid artery (ECA) $-\mathrm{SVG}-\mathrm{S}_{1} \mathrm{SCA}(\mathrm{n}=$ 1). Intraoperative aneurysm rupture occurred in 3 cases. One bypass occluded intraoperatively due to graft twisting and was opened and reanastamosed.

All bypasses remained patent postoperatively. Two patients had postoperative epidural hematomas, one requiring a return to the operating room for a hemicraniectomy. A number of patients were comatose following surgery due to intraoperative aneurysm rupture $(n=3)$, postoperative aneurysm rupture $(n=2)$, ischemic complications $(n=4)$, and indeterminate reasons $(n=7)$. Many of these patients later died shortly after surgery (final mortality rate was $58 \%$ ). Thus, it is difficult, if not impossible, to accurately quantify the rate of ONP in this population of patients.

\section{Brainstem CMs}

Fourteen patients had brainstem CMs resected via the OTT (Table 3). The average age was 50 years and just over half of the patients $(57 \%)$ were female. All patients were symptomatic with radiographic evidence of CM bleeding. More than half of the patients (64.3\%) had a poor preoperative mRS score. CM locations included the midbrain (n $=10)$ and the pontomesencephalic junction $(n=4)$. One of the midbrain CMs extended cranially into the thalamus. The majority of the midbrain CMs involved the ipsilateral cerebral peduncle (Fig. 5). An OZ craniotomy was per- 

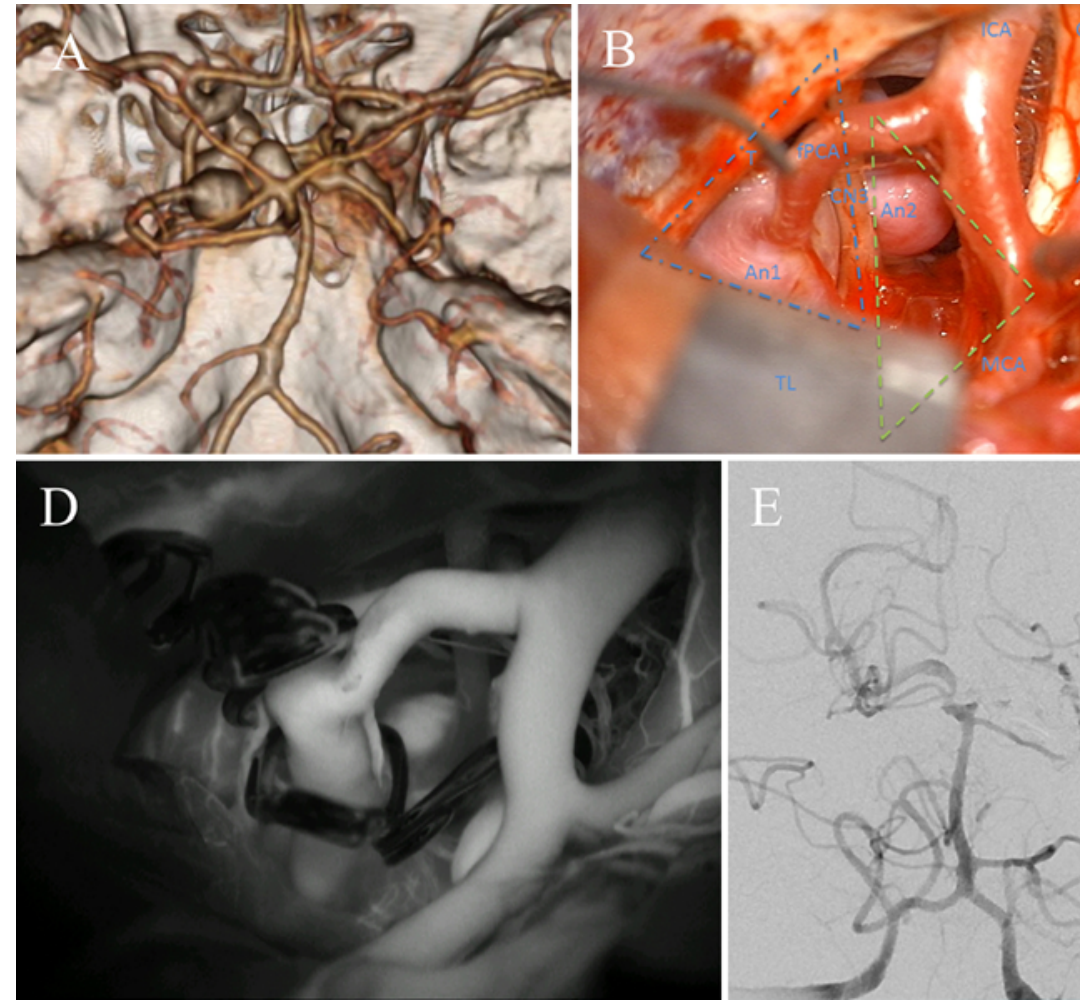

FIG. 2. $P C A$ aneurysm. A 73-year-old woman presented with a large dolichoectatic left $P_{2} P C A$ aneurysm and a smaller basilar bifurcation aneurysm detected incidentally $(A)$. She was referred for surgery after a failed attempt at endovascular therapy. The aneurysms were exposed through an OZ-pretemporal approach, and posterior retraction on the temporal lobe (TL) exposed the fetal PCA (fPCA) and aneurysms (B). The PCA aneurysm (An1) can be seen within the OTT (blue outline) and the basilar apex aneurysm (An2) can be seen within the COT (green outline). Note the large thalamoperforator at the proximal end of the aneurysm. Both aneurysms were treated with clip reconstruction (C). The basilar aneurysm was clipped successfully with two clips. Note the large circumflex perforator (arrow) originating from the lateral wall of the aneurysm. The $\mathrm{P}_{2} \mathrm{~A}$ segment was reconstructed with straight fenestrated clips stacked around the circumflex perforator laterally and a bayoneted fenestrated clip around the thalamoperforator medially. Aneurysm occlusion and patency of parent and perforating arteries was confirmed intraoperatively with ICG videoangiography (D) and postoperatively with DSA (E). The patient had an uneventful postoperative course and made a full recovery. $\mathrm{FL}=$ frontal lobe; $\mathrm{T}=$ tentorium. Figure is available in color online only.

formed in 11 cases and a pterional craniotomy was performed in 3 cases. An anterior petrosectomy (Kawase approach) was added to the pterional craniotomy in 2 cases to extend the view for the pontomesencephalic CMs.
All of the CMs were completely resected except for 2 cases in which there was residual disease. One of these patients underwent a second surgery via the same approach. The most common immediate complications were cranial
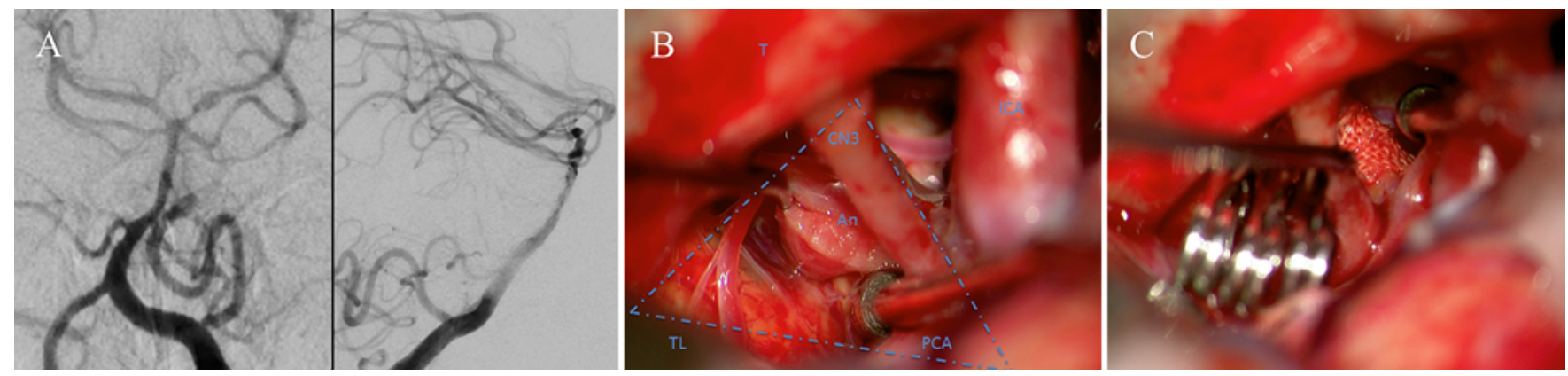

FIG. 3. Basilar blister aneurysm. This 44-year-old man presented in a coma with SAH and a history of intravenous drug abuse. Angiography revealed two aneurysmal lesions involving the left $\mathrm{P}_{2} \mathrm{PCA}$ and basilar quadrifurcation $(\mathbf{A})$. The OTT was opened through a left $\mathrm{OZ}$ craniotomy and a blister aneurysm (An) was found within the OTT (blue outline) arising from the posterior wall of the quadrification, covered with a thrombus cap (B). The OTT was the optimal working space for wrapping the blister aneurysm by passing a muslin sling behind the aneurysm (C). The tails of the sling were pulled snuggly and secured with 3 stacked clips. Despite the lesion's location in the midline, the OTT provided the best visualization and access. The $\mathrm{P}_{2}$ PCA dilation was also wrapped, although it did not appear to be the rupture site. Figure is available in color online only. 
TABLE 2. PCA and SCA bypass

\begin{tabular}{|c|c|c|}
\hline Variable & No. & $\%$ \\
\hline No. of patients & 24 & \\
\hline Mean age (yrs) & 59 & \\
\hline \multicolumn{3}{|l|}{ Sex } \\
\hline Females & 7 & 29 \\
\hline Males & 17 & 71 \\
\hline \multicolumn{3}{|l|}{ Pathology } \\
\hline VBI & 3 & 13 \\
\hline Basilar trunk aneurysm & 13 & 54 \\
\hline Basilar tip aneurysm & 4 & 17 \\
\hline $\mathrm{P}_{1} \mathrm{PCA}$ aneurysm${ }^{*}$ & 2 & 8 \\
\hline $\mathrm{s}_{1} \mathrm{SCA}$ aneurysm & 2 & 8 \\
\hline \multicolumn{3}{|l|}{ Preop mRS score } \\
\hline Good & 8 & 33 \\
\hline Poor & 16 & 67 \\
\hline \multicolumn{3}{|l|}{ Bypass } \\
\hline $\mathrm{M}_{2}$ MCA-RAG-P $\mathrm{PCA}$ & 8 & 33 \\
\hline $\mathrm{M}_{2}$ MCA-SVG-P ${ }_{2}$ PCA & 3 & 13 \\
\hline STA-P ${ }_{2}$ PCA & 5 & 21 \\
\hline STA-S ${ }_{1}$ SCA & 3 & 13 \\
\hline $\mathrm{s}_{1}$ SCA-P ${ }_{2} \mathrm{PCA}$ & 1 & 4 \\
\hline$V_{3}$ VA-RAG-S $S C A$ & 1 & 4 \\
\hline$V_{3}$ VA-SVG-P ${ }_{2} P C A$ & 1 & 4 \\
\hline ATA-S ${ }_{1}$ SCA & 1 & 4 \\
\hline ECA-SVG-S, SCA & 1 & 4 \\
\hline \multicolumn{3}{|l|}{ Outcome } \\
\hline Bypass patency & 24 & 100 \\
\hline mRS score stable or worse at follow-up & 18 & 75 \\
\hline Poor outcome (mRS score 3-6) & 17 & 71 \\
\hline Death & 14 & 58 \\
\hline
\end{tabular}

* These PCA aneurysms are outside the OTT and are therefore not classified with the other PCA aneurysms.

nerve palsies: ONP $(n=2), C N$ VI palsy $(n=2)$, and $C N$ VII palsy $(\mathrm{n}=2)$. Additionally, 2 patients had bleeding complications, 1 patient had hemiparesis, and 1 patient had aphasia. At follow-up, 1 patient had persistent hemiparesis and 1 patient had persistent ONP. At discharge, all mRS scores were stable or improved except 1 patient in whom the mRS score went from 2 to 3 . At follow-up, all $\mathrm{mRS}$ scores were stable or improved compared to preoperatively except 1 patient who had devastating anoxic neurological injury following a pulmonary embolism and cardiac arrest. The majority of patients had a good clinical outcome $(79 \%)$ and there were no deaths.

\section{Tentorial Region dAVFs}

Four patients with tentorial region dAVFs were accessed via the OTT for surgical clipping (Table 4). The fistulas drained into the superior petrosal sinus (SPS), tentorial sinus (TS), cavernous sinus (CS), and sphenobasal sinus (SBS). One patient presented with hemorrhage and poor mRS score. Two patients presented with symptoms of venous engorgement, including proptosis in the case of the CS fistula and blurry vision in the case of the SBS fistula. Two patients had failed endovascular treatment (Fig. 6). After surgery, all fistulas were completely occluded. The only complication was 1 patient who sustained an ONP. All patients were stable or improved at follow-up.

\section{Discussion \\ Main Findings}

This study defines the OTT as an important anatomical triangle and surgical workspace for vascular lesions in and around the crural and ambient cisterns. Our study demonstrates that a variety of posterior circulation/brainstem cerebrovascular pathologies may be approached anteriorly via the OTT. The final clinical outcome for patients with aneurysms, CMs, and dAVFs was good and the clinical outcome for patients who underwent bypass was poor. Our overall rate of permanent ONP of $8.3 \%$ is consistent with other larger series of similar pathology (see below). Although the OZ approach to the OTT was developed as an alternative to subtemporal access for PCA-SCA bypasses, and although these patients had some of the worst outcomes as a result of their severe pathology (e.g., dolichoectatic basilar trunk aneurysms), execution of their bypasses was facilitated by this triangle. Other, less severe pathologies exposed and treated through this triangle were associated with excellent patient outcomes.

\section{Aneurysms}

PCA aneurysms are unique in that they can be approached anteriorly, laterally, or posteriorly depending on the involved segment. There have only been a few published surgical series of significant size. . $7,7,25,28,32$ Wang et al. reported 30 patients with 30 aneurysms. ${ }^{28}$ Approaches included pterional $(\mathrm{n}=13)$, subtemporal $(\mathrm{n}=8)$, frontotemporal-OZ $(\mathrm{n}=5)$, combined pterional/subtemporal (n $=2$ ), posterior interhemispheric approach (PIA; $n=1$ ), and transtemporal $(\mathrm{n}=1)$. The rate of ONP was $16.7 \%$. The authors favored the pterional approach for $\mathrm{P}_{1}$ and some $\mathrm{P}_{1}-\mathrm{P}_{2}$ aneurysms and the other approaches for $\mathrm{P}_{1}-\mathrm{P}_{2}$ and beyond. Goehre et al. reported 121 patients with 135 PCA aneurysms, of which 63 were treated with microsurgery. ${ }^{7}$ Approaches included subtemporal $(n=33)$, pterional $(n=12)$, lateral supraorbital $(\mathrm{n}=10)$, and PIA $(\mathrm{n}=3)$; "modified temporal approaches" were used for bypass $(\mathrm{n}=2)$. The rate of ONP was $14.3 \%$. The authors preferred frontotemporal or subtemporal approaches for proximal $\left(\mathrm{P}_{1}\right.$ or $\left.\mathrm{P}_{2}\right)$ aneurysms. In a separate publication, the same authors focused on the subtemporal approach. ${ }^{8}$ The subtemporal approach was chosen for aneurysms that were below the PCP and in close proximity to the tentorium. The aneurysms themselves spanned from $\mathrm{P}_{1}$ to $\mathrm{P}_{3}$. Although the subtemporal approach puts significant retraction risk on the temporal lobe and traversing veins, the authors only reported a $6 \%$ incidence of temporal lobe contusion. There was, however, a high risk (35\%) of PCA infarction. The ONP rate was again $14.3 \%$. The supracerebellar infratentorial (SCIT) approach has also been described for $\mathrm{P}_{2}$ and $\mathrm{P}_{2}-\mathrm{P}_{3}$ aneurysms. ${ }^{29}$ Chang et al. published a series of 34 distal PCA aneurysms $\left(\mathrm{P}_{2}-\mathrm{P}_{4}\right)$ showing a higher rate of compli- 

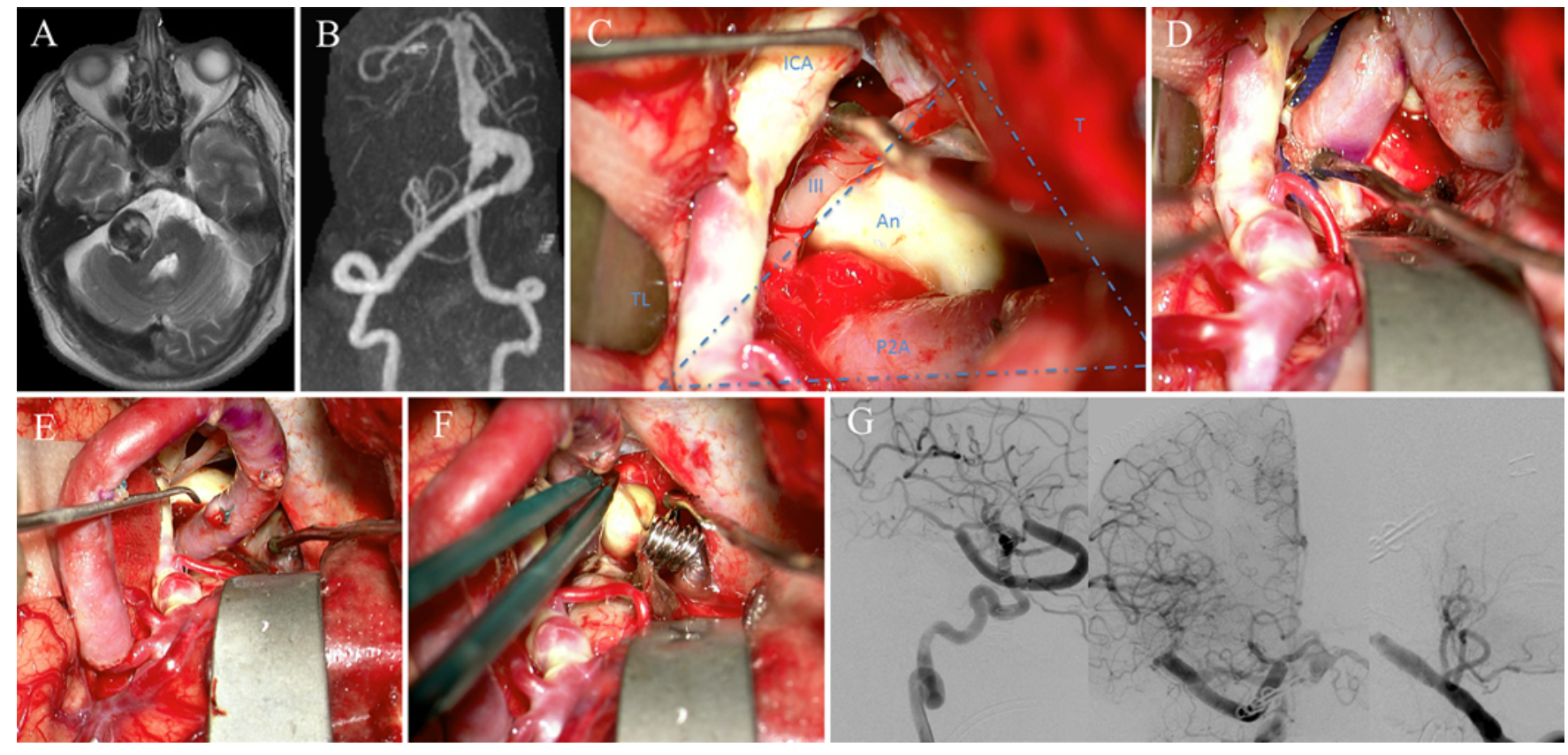

FIG. 4. MCA-PCA bypass. This 69 -year-old man presented with mass effect symptoms from this giant, dolichoectatic, thrombotic basilar trunk aneurysm shown on axial MRI (A). MR angiography demonstrated an irregular intraaneurysmal lumen with minimal saccular dilation, indicating its thrombotic core (B). An $M_{2}$ MCA-SVG-P ${ }_{2}$ PCA bypass with distal aneurysm occlusion was planned. He failed his preoperative Allen test and the radial arteries could not be used. A right OZ craniotomy and transsylvianpretemporal approach exposed the OTT (blue outline), which was filled with atherosclerotic distal basilar artery aneurysm (An) and the $P_{2} A$ recipient vessel (C). The distal end-to-side anastomosis to $P_{2} A$ was completed in the OTT (D), and the proximal end-toside anastomosis to the $M_{2}$ MCA was competed in the sylvian fissure $(E)$. The distal basilar trunk was followed through the OTT and the aneurysm was distally occluded with 3 clips (F). Postoperative angiography (right ICA anteroposterior, lateral, and left VA anteroposterior) showed a patent bypass that filled the basilar apex retrograde and stagnant flow into the basilar trunk aneurysm (G). Despite administering clopidogrel in the immediate postoperative period to slow the aneurysm thrombosis, he suffered midbrain perforator infarcts, remained comatose, and his family withdrew support. Figure is available in color online only.

cations with distal occipital artery-PCA bypass versus reconstructive treatments directly addressing the aneurysm. ${ }^{4}$

In the present series, 18 PCA aneurysms $\left(\mathrm{P}_{1}-\mathrm{P}_{2}\right.$ junction through $\mathrm{P}_{3}$ ) were treated via the OTT. This represents $29 \%$ of the 62 total PCA aneurysms treated in the senior author's experience. Other approaches included OZ or pterional not via the OTT $(n=33)$, subtemporal $(n=5)$, PIA ( $=5)$, and SCIT $(\mathrm{n}=1)$. An OZ or pterional approach not via the OTT was typically used for $\mathrm{P}_{1}$ aneurysms, the subtemporal approach was typically used for $\mathrm{P}_{2 \mathrm{P}}$ aneurysms, and the PIA and SCIT approaches were used for more distal aneurysms. We favor the OZ-pretemporal approach over the subtemporal approach, which lessens the retraction on the temporal lobe. ${ }^{30}$ Of course, the approach will need to be tailored to the specific aneurysm, morphology, and local anatomy.

\section{PCA and SCA Bypass}

Revascularization of the basilar quadrifurcation is performed for either complex posterior circulation aneurysms or VBI. ${ }^{11-15,18,22,23,26,30}$ Either the SCA or PCA can be the recipient artery depending on caliber, pathology, and approach. The STA-SCA bypass via the subtemporal approach is the prototypical posterior circulation bypass. ${ }^{30}$ The benefits of this bypass include a minimalistic craniotomy, a direct path from the STA origin to the SCA, and a single anastomosis. On the other hand, the STA may not provide enough flow to revascularize the entire posterior circulation. Another drawback results from inevitable retraction of the temporal lobe with resultant edema and possible venous injury. This retraction increases if the PCA is the target recipient vessel as it rides higher above the tentorium. Alternatively, a pretemporal approach utilizing the OZ craniotomy is another option for both PCA and SCA bypass and reduces the degree of temporal lobe retraction. The pretemporal approach provides direct access to the OTT. In a previous publication by the senior author, the subtemporal and pretemporal approaches for deep posterior circulation bypasses were compared both anatomically and clinically. ${ }^{30}$ The pretemporal approach optimized exposure of the $\mathrm{P}_{2 \mathrm{~A}}$ segment of the PCA, whereas the subtemporal approach optimized exposure of the lateral pontomesencephalic segment of the SCA. Each approach was able to obtain similar working depths and exposed segment length. The PCA was a larger recipient. The pretemporal approach offered less brain shift, retraction pressure, and volume of temporal lobe edema. The occipital artery may also be utilized for a distal PCA bypass, ${ }^{4,27}$ but like the SCA, is unlikely to provide enough flow for the entire basilar quadrifurcation.

In the present series, 24 bypasses were performed to either the PCA or SCA for pathology outside of the OTT. This represents $4.2 \%$ of the total 575 bypasses performed 
by the senior author. Not only are these bypasses technically difficult to perform, but the patient population has the most severe neurovascular disease, as demonstrated by the poor preoperative mRS score. The clinical outcome of many of the patients with dolichoectatic basilar trunk aneurysms is dismal and has been previously reported..$^{15}$ A number of different approaches have been taken with basilar trunk aneurysms specifically. With many years of experience, the approach with the lowest final mortality rate, which was still $62 \%$, included a distal clip occlusion of the basilar artery through the COT in conjunction with a bypass through the OTT, usually from the MCA to the PCA. ${ }^{15}$ Patients with other pathologies, such as VBI and giant, unclippable posterior circulation aneurysms, are also very sick, making this entire group of patients the most difficult to treat. Bypass into the OTT is technically feasible, but there is certainly much room for improvement with regard to understanding and treating these difficult disease processes. Given the high morbidity and mortality, the treatment of dolichoectatic basilar trunk aneurysms should be concentrated in select few centers where concerted effort between neurosurgeons, endovascular surgeons, neurologists, and interventional neuroradiologists to study aneurysm morphology, hemodynamics, and outcomes will hopefully advance our therapy.

\section{Brainstem CMs}

The OZ approach to anterior midbrain CMs has been well described. ${ }^{1,2,5,6,17,19}$ While the COT is used to approach the anteromedial midbrain, the OTT is used to approach the anterolateral midbrain. In a series of 260 brainstem CMs resected at a single institution over nearly 30 years, there were $48(18.5 \%)$ midbrain lesions and 31 (11.9\%) pontomesencephalic lesions. ${ }^{1}$ These anterior midbrain lesions involving the cerebral peduncle were approached via an $\mathrm{OZ}$ craniotomy, whereas the other midbrain lesions were approached via a SCIT approach. All of the pontomesencephalic lesions were approached via a SCIT approach, suggesting they were all in the lateral or posterior pons, rather than the anterior pons. The same authors later published outcomes for a larger series including 397 patients. ${ }^{31}$ A new postoperative deficit was found in 55\% of the midbrain lesions and was most likely to be a cranial nerve deficit. This deficit persisted in 36\%. At long-term follow-up 55\% of patients with midbrain lesions were improved and $45 \%$ were the same or worse, demonstrating that these lesions are difficult to treat without morbidity, even in the best hands. A supplemental surgical video demonstrates the resection of a midbrain CM through this operative corridor (Video 1).

VIDEO 1. Clip showing the complete resection of a mesencephalic CM through the OTT in a middle-aged woman presenting with acute hemiparesis. Copyright Michael T. Lawton. Published with permission. Click here to view.

In the present series, 14 brainstem CMs (10 midbrain, 4 pontomesencephalic junction) were resected via the OTT. This represents $7.4 \%$ of the 190 total brainstem CMs and $33 \%$ of the 43 midbrain/pontomesencephalic CMs treated in the senior author's experience. The other lesions were approached via either a PIA $(n=5)$ for midbrain CMs with
TABLE 3. Brainstem CMs

\begin{tabular}{lcc}
\hline \multicolumn{1}{c}{ Variable } & No. & $\%$ \\
\hline No. of patients & 14 & \\
\hline Mean age (yrs) & 50 & \\
\hline Sex & & \\
\hline Females & 8 & 57 \\
\hline Males & 6 & 43 \\
\hline Preoperative mRS score & & \\
\hline Good & 5 & 36 \\
\hline Poor & 9 & 64 \\
\hline CM location & & \\
\hline Midbrain & 10 & 71 \\
\hline Pontomesencephalic & 4 & 29 \\
\hline Approach & 11 & \\
\hline OZ & 1 & 7 \\
\hline Pterional & 2 & 14 \\
\hline Pterional/Kawase & & \\
\hline Outcome & 2 & 14 \\
\hline Residual CM & 1 & 7 \\
\hline Retreatment & 1 & 7 \\
\hline Permanent ONP & 13 & 93 \\
\hline mRS score stable or improved at follow-up & 11 & 79 \\
\hline Good outcome (mRS score 0-2) & 0 \\
\hline Death & & \\
\hline & & \\
\hline & & \\
\hline
\end{tabular}

thalamic extension or more commonly the SCIT approach $(\mathrm{n}=24)$ for $\mathrm{CMs}$ of the lateral and posterior midbrain. The anterior approach via the OTT provides the best view of the anterolateral midbrain, which is necessary to resect the $\mathrm{CM}$ while protecting the cerebral peduncle. It requires mobilization of the PCA, SCA, and perforators as well as working alongside and past CN III. Motor mapping of the cerebral peduncle can be utilized as well to prevent injury. ${ }^{21}$

\section{Tentorial Region dAVFs}

Tentorial region dAVFs adjacent to the OTT include those of the TS, incisura, SPS, sphenoparietal sinus, SBS, and CS. The TS (Type 4) is poorly described and recognized, but may run anywhere in the tentorium, either laterally or medially. Similarly, incisural dAVFs (Type 6) are also poorly described and may in fact be fistulas of the marginal TS. TS and incisural dAVFs are similar in that they both are associated with an intrinsic TS, both have variable anatomy, and both drain supratentorially. They are differentiated by surgical approach. ${ }^{24}$ The SPS dAVF (Type 5) typically drains infratentorially into the petrosal vein. The SBS is a variant of the sphenoparietal sinus that exits the cranium inferiorly via the sphenoidal emissary veins toward the pterygoid plexus. The SBS runs through the middle fossa floor and is therefore just lateral to the OTT. The CS is at the anteroinferior boundary of the OTT where CN III pierces the oculomotor triangle.

Tentorial dAVFs are often difficult to treat curatively by endovascular means, ${ }^{3}$ and in these cases may require 

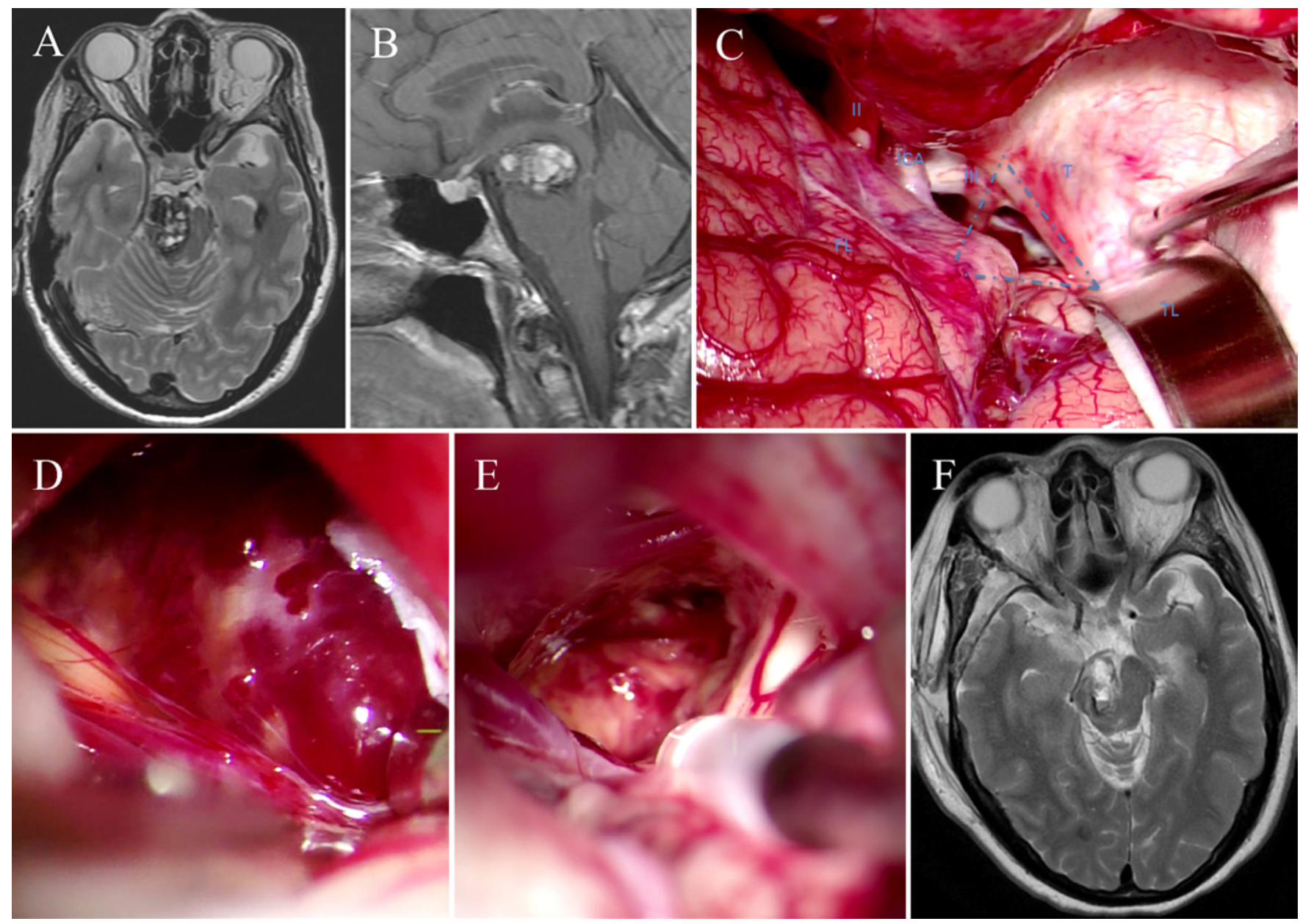

FIG. 5. Midbrain CM. A 49-year-old woman presented with sudden onset of left hemiparesis and left facial droop. MRI of the brain demonstrated a hemorrhagic lesion within the right midbrain displacing the right cerebral peduncle laterally $(\mathbf{A})$. The CM was exposed through a right OZ-pretemporal approach, with opening of the OTT with temporal lobe retraction (B). The lesion protruded into the interpeduncular cistern with access between CN III, the tentorium, and the medial edge of the cerebral peduncle (C). The CM was removed completely though the working space of the OTT (D). The resection cavity was clean visually at surgery (E) and on postoperative MRI (F). The patient had an uncomplicated hospital course and her hemiparesis has improved at late follow-up. Figure is available in color online only.

open surgery. The transsylvian approach has been described for accessing dAVFs of the anterior tentorium/ sphenoid ridge. ${ }^{9,16,24}$ The TS dAVF and incisural dAVF are differentiated in that the former is usually approached by a torcular craniotomy with a supratentorial-infraoccipital approach, whereas the latter is approached by an anterior, transsylvian approach, usually via the OTT.16,24 The SPS dAVF is usually approached via an extended retrosigmoid $^{16,24}$ or presigmoid ${ }^{10}$ approach. When using the OTT to approach these fistulas, it should be confirmed that the fistula connection is in or around the OTT to ensure that the appropriate disconnection is made.

TABLE 4. Tentorial region dAVFs

\begin{tabular}{ccclcccc}
\hline & & & & & \multicolumn{2}{c}{ mRS Score } \\
\cline { 5 - 8 } Case No. & Age (yrs), Sex & Preop mRS Score & Presentation & dAVF Outflow & Complication & Discharge & Last \\
\hline $1^{*}$ & $87, \mathrm{~F}$ & 2 & Missing data & SPS & None & 2 & 1 \\
\hline 2 & $8, \mathrm{~F}$ & 2 & Proptosis & CS & None & 1 & 1 \\
\hline 3 & $68, \mathrm{M}$ & 5 & Hemorrhage & TS & None & 4 & 3 \\
\hline 4 & $2, \mathrm{M}$ & 2 & Blurry vision & SBS & ONP & 1 & 0 \\
\hline
\end{tabular}

All patients underwent dAVF occlusion.

${ }^{*}$ Records not available. 

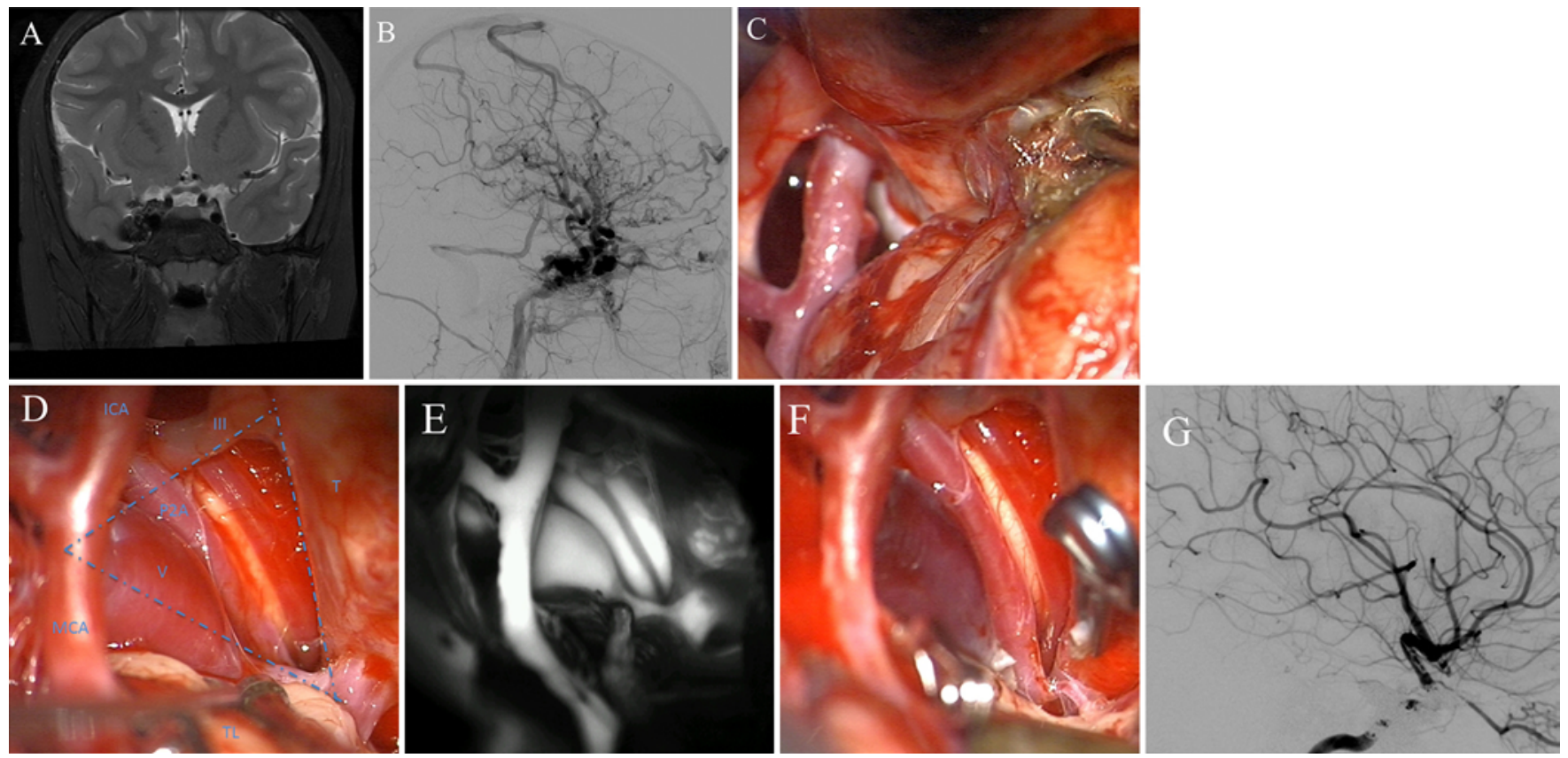

FIG. 6. Tentorial dAVF. This 8-year-old girl had a right carotid-cavernous fistula that embolized multiple times with incomplete obliteration. Coils filled the right CS and expanded its lateral wall, as noted on coronal MRI (A). She was referred for surgical treatment when angiography (right ICA angiogram, lateral view) revealed persistent retrograde cortical venous drainage to the basal vein of Rosenthal and cortical veins, including the vein of Labbe and Trolard (B). A right OZ-pretemporal approach exposed the coils in the lateral wall of the CS (C). Dissection into the OTT (blue outline) identified the arterialized incisural vein leading to a venous varix $(V)$ in the basal vein just above the $P_{2}$ PCA (D). ICG videoangiography confirmed the site of shunt flow out of the CS through this vein (E). The vein was clip-occluded, cauterized, and divided within the OTT (F). The varix turned dark blue after clipping. Postoperative angiography demonstrated no residual filling of the carotid-cavernous fistula (G). Figure is available in color online only.

\section{Limitations}

Our study is limited by its retrospective nature, small number of patients, and nonstandardized methods of judging angiographic and clinical outcome. Furthermore, we do not have comparison groups to demonstrate other surgical approaches for similar pathology. Finally, we do not have operative report information on specific techniques to widen the OTT, such as uncal resection, which would be informative.

\section{Conclusions}

The OTT is an important anatomical triangle and surgical workspace for vascular lesions in and around the crural and ambient cisterns. The OTT can be used to approach a wide variety of vascular pathologies in the region of the basilar quadrifurcation and anterolateral midbrain.

\section{References}

1. Abla AA, Lekovic GP, Turner JD, de Oliveira JG, Porter R, Spetzler RF: Advances in the treatment and outcome of brainstem cavernous malformation surgery: a single-center case series of 300 surgically treated patients. Neurosurgery 68:403-415, 2011

2. Abla AA, Turner JD, Mitha AP, Lekovic G, Spetzler RF: Surgical approaches to brainstem cavernous malformations. Neurosurg Focus 29(3):E8, 2010

3. Cannizzaro D, Brinjikji W, Rammos S, Murad MH, Lanzino
G: Changing clinical and therapeutic trends in tentorial dural arteriovenous fistulas: a systematic review. AJNR Am J Neuroradiol 36:1905-1911, 2015

4. Chang SW, Abla AA, Kakarla UK, Sauvageau E, Dashti SR, Nakaji P, et al: Treatment of distal posterior cerebral artery aneurysms: a critical appraisal of the occipital artery-to-posterior cerebral artery bypass. Neurosurgery 67:16-26, 2010

5. Davies JM, Kim H, Lawton MT: Surgical treatment of cerebral cavernous malformations. J Neurosurg Sci 59:255-270, 2015

6. Garcia RM, Ivan ME, Lawton MT: Brainstem cavernous malformations: surgical results in 104 patients and a proposed grading system to predict neurological outcomes. Neurosurgery 76:265-278, 2015

7. Goehre F, Jahromi BR, Lehecka M, Lehto H, Kivisaari $\mathrm{R}$, Andrade-Barazarte $\mathrm{H}$, et al: Posterior cerebral artery aneurysms: treatment and outcome analysis in 121 patients. World Neurosurg 92:521-532, 2016

8. Goehre F, Lehecka M, Jahromi BR, Lehto H, Kivisaari R, Hijazy F, et al: Subtemporal approach to posterior cerebral artery aneurysms. World Neurosurg 83:842-851, 2015

9. Gross BA, Du R: Surgical treatment of high grade dural arteriovenous fistulae. J Clin Neurosci 20:1527-1532, 2013

10. Hwang G, Kang HS, Oh CW, Kwon OK: Surgical obliteration in superior petrosal sinus dural arteriovenous fistula. J Korean Neurosurg Soc 49:222-225, 2011

11. Kalani MYS, Hu YC, Spetzler RF: A double-barrel superficial temporal artery-to-superior cerebellar artery (STA-SCA) and STA-to-posterior cerebral artery (STA-PCA) bypass for revascularization of the basilar apex. J Clin Neurosci 20:887-889, 2013

12. Kalani MYS, Ramey W, Albuquerque FC, McDougall CG, Nakaji P, Zabramski JM, et al: Revascularization and aneu- 
rysm surgery: techniques, indications, and outcomes in the endovascular era. Neurosurgery 74:482-498, 2014

13. Kalani MYS, Spetzler RF: Internal carotid artery-toposterior cerebral artery bypass for revascularization of the brainstem. J Clin Neurosci 24:151-154, 2016

14. Kawashima M, Rhoton AL Jr, Tanriover N, Ulm AJ, Yasuda A, Fujii K: Microsurgical anatomy of cerebral revascularization. Part II: posterior circulation. J Neurosurg 102:132-147, 2005

15. Lawton MT, Abla AA, Rutledge WC, Benet A, Zador Z, Rayz VL, et al: Bypass surgery for the treatment of dolichoectatic basilar trunk aneurysms: a work in progress. Neurosurgery 79:83-99, 2016

16. Lawton MT, Sanchez-Mejia RO, Pham D, Tan J, Halbach VV: Tentorial dural arteriovenous fistulae: operative strategies and microsurgical results for six types. Neurosurgery 62 (3 Suppl 1):110-125, 2008

17. Ohmura T, Hirakawa K, Ohta M, Utsunomiya H, Fukushima $\mathrm{T}$ : Cavernous malformation of the ventral midbrain successfully removed via a transsylvian-transpeduncular approach: case report. Neurol Med Chir (Tokyo) 48:569-572, 2008

18. Ota N, Goehre F, Miyazaki T, Kinoshita Y, Matsukawa H, Yanagisawa T, et al: Bypass revascularization applied to the posterior cerebral artery. World Neurosurg 96:460-472, 2016

19. Porter RW, Detwiler PW, Spetzler RF, Lawton MT, Baskin JJ, Derksen PT, et al: Cavernous malformations of the brainstem: experience with 100 patients. J Neurosurg 90:50-58, 1999

20. Post N, Russell SM, Jafar JJ: Role of uncal resection in optimizing transsylvian access to the basilar apex: cadaveric investigation and preliminary clinical experience in eight patients. Neurosurgery 56 (2 Suppl):274-280, 2005

21. Quinones-Hinojosa A, Lyon R, Du R, Lawton MT: Intraoperative motor mapping of the cerebral peduncle during resection of a midbrain cavernous malformation: technical case report. Neurosurgery 56:E439, 2005

22. Ramanathan D, Ciporen J, Ghodke B, Ellenbogen RG, Sekhar LN: Treatment of coil embolization failed recurrent giant basilar tip aneurysms with bypass and surgical occlusion. $\mathbf{J}$ Neurointerv Surg 2:237-241, 2010

23. Rodríguez-Hernández A, Huang C, Lawton MT: Superior cerebellar artery-posterior cerebral artery bypass: in situ bypass for posterior cerebral artery revascularization. J Neurosurg 118:1053-1057, 2013

24. Rutkowski MJ, Jian B, Lawton MT: Surgical management of cerebral dural arteriovenous fistulae. Handb Clin Neurol 143:107-116, 2017

25. Sanai N, Tarapore P, Lee AC, Lawton MT: The current role of microsurgery for posterior circulation aneurysms: a selective approach in the endovascular era. Neurosurgery 62:1236-1253, 2008

26. Takeuchi S, Tanikawa R, Tsuboi T, Noda K, Oda J, Miyata S, et al: Superficial temporal artery to proximal posterior cerebral artery bypass through the anterior temporal approach. Surg Neurol Int 6:95, 2015

27. Vishteh AG, Smith KA, McDougall CG, Spetzler RF: Distal posterior cerebral artery revascularization in multimodality management of complex peripheral posterior cerebral artery aneurysms: technical case report. Neurosurgery 43:166-170, 1998

28. Wang WX, Xu BN, Wang FY, Wu C, Sun ZH: Microsurgical management of posterior cerebral artery aneurysms: a report of thirty cases in modern era. Br J Neurosurg 29:406-412, 2015

29. Yonekawa Y, Roth P, Fandino J, Landolt H: Aneurysms of the posterior cerebral artery and approach selection in their microsurgical treatment: emphasis on the approaches: SAHEA and SCTTA. Acta Neurochir Suppl (Wien) 112:85-92, 2011

30. Zador Z, Lu DC, Arnold CM, Lawton MT: Deep bypasses to the distal posterior circulation: anatomical and clinical comparison of pretemporal and subtemporal approaches. Neurosurgery 66:92-101, 2010

31. Zaidi HA, Mooney MA, Levitt MR, Dru AB, Abla AA, Spetzler RF: Impact of timing of intervention among 397 consecutively treated brainstem cavernous malformations. Neurosurgery 81:620-626, 2017

32. Zhitao J, Yibao W, Anhua W, Shaowu O, Yunchao B, Renyi $\mathrm{Z}$, et al: Microsurgical subtemporal approach to aneurysms on the $\mathrm{P}_{2}$ segment of the posterior cerebral artery. Neurol India 58:242-247, 2010

\section{Disclosures}

The authors report no conflict of interest concerning the materials or methods used in this study or the findings specified in this paper.

\section{Author Contributions}

Conception and design: Lawton, Mascitelli. Acquisition of data: Gandhi. Analysis and interpretation of data: Mascitelli, Gandhi. Drafting the article: Mascitelli, Gandhi. Critically revising the article: all authors. Reviewed submitted version of manuscript: all authors. Approved the final version of the manuscript on behalf of all authors: Lawton. Statistical analysis: Mascitelli, Gandhi. Administrative/technical/material support: Gandhi. Study supervision: Lawton.

\section{Supplemental Information \\ Videos \\ Video 1. https://vimeo.com/257489246.}

\section{Companion Papers}

Tayebi Meybodi A, Gandhi S, Mascitelli J, Bozkurt B, Bot G, Preul MC, et al: The oculomotor-tentorial triangle. Part 1: microsurgical anatomy and techniques to enhance exposure. DOI: 10.3171/2018.1.JNS173139.

\section{Correspondence}

Michael T. Lawton: Barrow Neurological Institute, Phoenix, AZ. michael.lawton@barrowbrainandspine.com. 